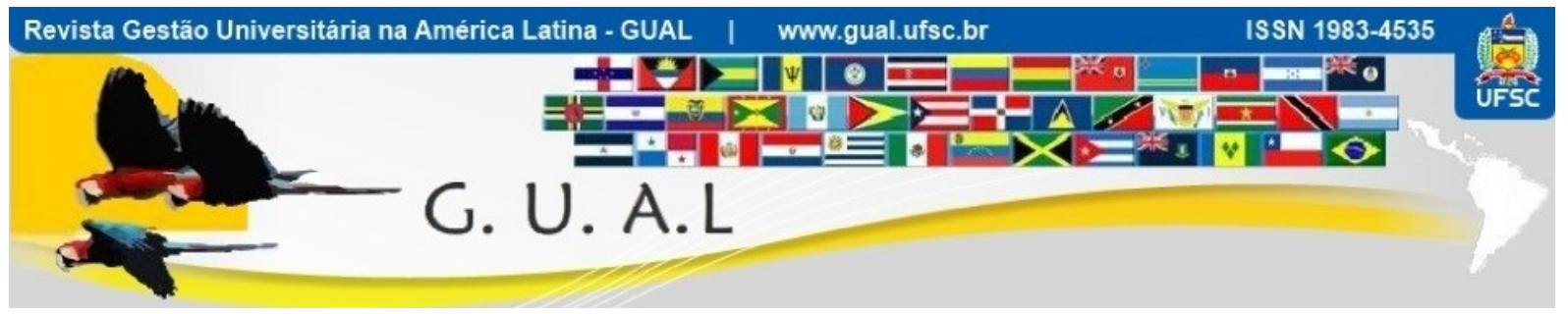

DOI: http://dx.doi.org/10.5007/1983-4535.2012v5n2p129

\title{
GESTÃO DE PESSOAS EM UM INSTITUTO FEDERAL DE EDUCAÇÃO, CIÊNCIA E TECNOLOGIA
}

\author{
PEOPLE MANAGEMENT IN A FEDERAL INSTITUTE OF \\ EDUCATION, SCIENCE AND TECHNOLOGY
}

Alessandra de Linhares Jacobsen, Doutora

Universidade Federal de Santa Catarina - UFSC

oajac@newsite.com.br

Raquel Lilian Barbi de Cerqueira, Mestre Instituto Federal de Educação, Ciência e Tecnologia de Santa Catarina - IF-SC raqlilian@gmail.com

Melissa Liotto, Mestre Instituto Federal de Educação, Ciência e Tecnologia de Santa Catarina - IF-SC melissaliotto@ifsc.edu.br

Simone Marques de Almeida, Mestre Instituto Federal de Educação, Ciência e Tecnologia de Santa Catarina - IF-SC simonemarquesalmeida@yahoo.com.br

Mércia Pereira, Mestre Universidade Federal de Santa Catarina - UFSC mercia.pereira@ufsc.br

Jose Marcos da Silva, Mestre Universidade Federal de Santa Catarina - UFSC jmarcos@setic.ufsc.br

Recebido em 04/novembro/2011

Aprovado em 30/abril/2012

Sistema de Avaliação: Double Blind Review

Esta obra está sob uma Licença Creative Commons Atribuição-Uso. 


\begin{abstract}
RESUMO
A área de administração de pessoas vem evoluindo desde 1900, passando pela criação de legislação trabalhista, departamento de pessoal, sistemas de recursos humanos, até o que hoje chamamos de gestão de pessoas. Assim, este estudo busca conhecer as políticas de gestão de pessoas na administração acadêmica e administrativa de um Instituto Federal de Educação, Ciência e Tecnologia, identificando as políticas de gestão utilizadas pelo governo federal voltadas para a administração de pessoas e a legislação aplicada ao Instituto. A metodologia adotada é de natureza bibliográfica, qualitativa-descritiva, com os dados coletados mediante a realização de uma pesquisa de campo do tipo aplicada e entrevista semiestruturada. Como resultados, são identificadas oportunidades de melhorias nas políticas de gestão de pessoas em um Instituto, considerando as políticas públicas do governo federal.
\end{abstract}

Palavras-chave: Gestão de pessoas. Políticas públicas. Institutos Federais.

\begin{abstract}
The area of people management has been evolving since 1900, through the creation of employment law, personnel department, human resource systems, to what we now call personnel management. Thus, this study seeks to understand the people management policies in academic administration and management of a Federal Institute of Education, Science and Technology, identifying management policies used by the federal government aimed at managing people and the law applied to the Institute. The methodology adopted is bibliographic, qualitative, descriptive, and data were collected through a field applied research and semi-structured interview. As a result, opportunities for improvement are identified in the policies of managing people in an institute, considering the public policy of the federal government.
\end{abstract}

Keywords: Management of people. Public policy. Federal Institutes. 


\section{GESTÃO DE PESSOAS EM UM INSTITUTO FEDERAL DE EDUCAÇÃO, CIÊNCIA E

\section{INTRODUÇÃO}

As políticas de gestão de pessoas na administração acadêmica e administrativa das Instituições Federais de Ensino englobam uma série de diretrizes, normas, princípios e finalidades, que têm por função orientar os diversos processos e mecanismos da gestão de pessoas, buscando focar o que tem sido considerado por muitos um bem muito valorizado: as pessoas. Jacobsen (2006, p. 91) menciona:

Hoje, o senso comum é de que as pessoas constituem o bem de maior valor da organização, sendo o seu verdadeiro e único diferencial. Como conseqüência, a área de $\mathrm{RH}$ recebe um destaque cada vez maior, investindo de modo crescente nas atividades que desenvolve, sempre com o intuito de definir e manter um quadro de funcionários de alto nível.

$\mathrm{Na}$ área pública federal, percebe-se que as políticas buscam valorizar e tratar bem os servidores mediante a democratização das relações de trabalho, da carreira e remuneração, da gestão por competência, da avaliação de desempenho, saúde, previdência, e benefícios, entre outras medidas. Entretanto, a implementação dessas políticas vem sendo um dos desafios da gestão administrativa e acadêmica dos Institutos Federais de Educação, Ciência e Tecnologia. Como declara Laweler III (2003 apud DEMO, 2005, p. 49),

[...] tratar bem as pessoas ou os colaboradores é fundamental para a consecução da efetividade e do sucesso organizacional. Segundo o autor, tanto as pessoas quanto as organizações precisam ser bem sucedidas e, além disso, uma não pode alcançar o sucesso às expensas da outra. [...]. Requer também políticas que motivem as pessoas a darem o melhor de si em suas funções.

Portanto, nas políticas de gestão de pessoas no serviço público federal, é importante fomentar um equilíbrio entre o sucesso dos servidores e o da Instituição. É nesse sentido, e também ressaltando o tratar bem e a valorização dos servidores, que este estudo procura conhecer as políticas de gestão de pessoas na administração acadêmica e administrativa de um Instituto Federal, identificando as políticas públicas do governo federal, a legislação aplicada a esses institutos e as suas políticas internas.

Primeiramente, é descrita uma breve evolução histórica do departamento de pessoal à gestão de pessoas, identificando-se algumas características e mudanças. Na sequência, expõem-se as políticas de gestão de pessoas no âmbito do Instituto pesquisado, bem como as políticas públicas federais aplicadas. Abordam-se as seguintes políticas de gestão de pessoas: 


\section{GESTÃO DE PESSOAS EM UM INSTITUTO FEDERAL DE EDUCAÇÃO, CIÊNCIA E TECNOLOGIA \\ DOI: http://dx.doi.org/10.5007/1983-4535.2012v5n2p129}

recrutamento, seleção e integração, carreira, remuneração, capacitação e desenvolvimento, avaliação de desempenho, relações de trabalho e seguridade social. A seguir, é realizada uma síntese da história dos Institutos Federais de Educação, Ciência e Tecnologia, mostrando-se a importância social e tecnológica dessas instituições para o Brasil. Em seguida, são apresentados os procedimentos metodológicos utilizados no estudo e as análises e discussão dos resultados, buscando-se identificar oportunidades de melhorias nas políticas de gestão de pessoas em um Instituto, relacionando-as às políticas públicas do governo federal. Por fim, apontam-se algumas considerações finais.

\section{DO DEPARTAMENTO DE PESSOAL À GESTÃo DE PESSOAS}

Historicamente, a área de administração de pessoas vem evoluindo desde 1900, passando pela criação de legislações trabalhistas, departamento de pessoal, sistemas de recursos humanos, surgimento dos cargos de gerência em RH, até a chegada de reformas estruturais profundas de migração da função de Recursos Humanos para o que chamamos hoje de "gestão de pessoas" ou "gestão de talentos". O Quadro 1 demonstra os períodos clássicos que marcaram a gestão de pessoas no Brasil.

\begin{tabular}{|c|l|}
\hline Períodos & \multicolumn{1}{|c|}{ Características } \\
\hline $\begin{array}{c}\text { Pré/Jurídico/Trabalhista } \\
\text { (1930) }\end{array}$ & $\begin{array}{l}\text { Inexistência de legislação trabalhista; caracteriza-se pela } \\
\text { descentralização de funções e as demandas de pessoas estavam } \\
\text { relacionadas a tarefas simples. }\end{array}$ \\
\hline Burocrático (1930-1950) & $\begin{array}{l}\text { Há o advento de legislação trabalhista; surgem os primeiros } \\
\text { departamentos de pessoal, centrados na rotina de apontamentos de } \\
\text { frequências, pontualidade, absenteísmo, registro de ponto, } \\
\text { pagamento de salários. }\end{array}$ \\
\hline Tecnicista (1950-1960) & $\begin{array}{l}\text { Devido à implantação de numerosas plantas de fábrica, há maior } \\
\text { preocupação com a eficiência e com o desempenho. A } \\
\text { Administração de RH adota o conceito de Sistemas de Recursos } \\
\text { Humanos composta por recrutamento e seleção, treinamento, } \\
\text { avaliação de desempenho, programas de cargos e salários, higiene } \\
\text { industrial e serviço social. }\end{array}$ \\
\hline Sistêmico (1960-1980) & $\begin{array}{l}\text { Começam a surgir os cargos de gerência de recursos humanos; dá- } \\
\text { se ênfase ao treinamento, ao desenvolvimento e à alimentação do } \\
\text { trabalhador. }\end{array}$ \\
\hline $\begin{array}{c}\text { Relações Industriais } \\
\text { Integradas (1980-1990) }\end{array}$ & $\begin{array}{l}\text { Ocorre o alinhamento entre rotinas de pessoal, estrutura } \\
\text { organizacional e comportamento individual. São realizados } \\
\text { treinamentos sobre neuroses e patologia do trabalho. }\end{array}$ \\
\hline Reformas Estruturais & $\begin{array}{l}\text { O atual período é caracterizado por fatores de reformas estruturais } \\
\text { profundas, de migração da função de Recursos Humanos, } \\
\text { buscando-se novas identidades de denominação: "gestão de } \\
\text { pessoas", "gestão de talentos", "Departamento de Gente", entre }\end{array}$ \\
\hline
\end{tabular}




\section{GESTÃO DE PESSOAS EM UM INSTITUTO FEDERAL DE EDUCAÇÃO, CIÊNCIA E \\ TECNOLOGIA \\ DOI: http://dx.doi.org/10.5007/1983-4535.2012v5n2p129}

\section{outras.}

Quadro 1 Períodos clássicos que marcaram a gestão de pessoas no Brasil

Fonte: Adaptado pelos autores com base na visão de Limongi França (2007 apud BUHR, 2008, p. 26).

Analisando-se o Quadro 1, observa-se que a área de gestão de pessoas sofreu inúmeras mudanças, chegando ao século XXI e à Era do Conhecimento com a valorização, principalmente, do capital intelectual do ser humano nas organizações, isto é, das pessoas e de seus talentos. Assim, as pessoas deixam de ser meros instrumentos de trabalho e passam a ser o bem mais precioso das organizações. Como bem pontua Girardi (2008, p. 49), “A Gestão de Pessoas tem sido responsável pela excelência organizacional, pois investe atualmente no capital intelectual, que simboliza a importância do fator humano no século da informação e do conhecimento.".

A seguir, apresentam-se as políticas de gestão de pessoas na administração acadêmica e administrativa de um Instituto Federal, identificando-se as políticas públicas do governo federal voltadas para a gestão de pessoas e a legislação aplicada aos Institutos.

\section{GESTÃO DE PESSOAS NO INSTITUTO FEDERAL}

As políticas de gestão de pessoas são abordadas com denominações diferenciadas, dependendo da visão do autor, conforme descrito por Demo (2005, p. 51-53). Dessa forma, organizaram-se, no Quadro 2, apresentado abaixo, algumas das variações citadas pela autora:

\begin{tabular}{|c|l|}
\hline Autores & \multicolumn{1}{|c|}{ Políticas de gestão de pessoas (GP) } \\
\hline Singar e Ramsden (1972) & $\begin{array}{l}\text { Provisão de recursos humanos; treinamento e desenvolvimento; } \\
\text { recompensas e motivação; relações com os empregados; } \\
\text { condições de trabalho. }\end{array}$ \\
\hline Storey (1992a) & $\begin{array}{l}\text { Seleção; remuneração; condições de trabalho; gerenciamento do } \\
\text { trabalho; relações com os empregados; plano de carreiras; } \\
\text { comunicação; projeto do trabalho; gerenciamento de conflitos; } \\
\text { treinamento e desenvolvimento; gerenciamento de intervenções. }\end{array}$ \\
\hline Sisson (1994) & $\begin{array}{l}\text { Seleção; avaliação de desempenho; treinamento; sistema de } \\
\text { recompensas e beneficios; participação e envolvimento dos } \\
\text { empregados/comunicação. }\end{array}$ \\
\hline Robbins (1999) & $\begin{array}{l}\text { Práticas de seleção; programas de treinamento e e } \\
\text { desenvolvimento; avaliação de desempenho; interface sindicato- } \\
\text { administração. }\end{array}$ \\
\hline Ulrich (2001) & $\begin{array}{l}\text { Contratação; desenvolvimento; remuneração; eficácia } \\
\text { organizacional; comunicações; plano organizacional; relações } \\
\text { com os empregados; relações com os sindicatos; segurança e } \\
\text { tecnologia. }\end{array}$ \\
\hline
\end{tabular}




\section{GESTÃO DE PESSOAS EM UM INSTITUTO FEDERAL DE EDUCAÇÃO, CIÊNCIA E TECNOLOGIA \\ DOI: http://dx.doi.org/10.5007/1983-4535.2012v5n2p129}

\begin{tabular}{|c|l|}
\hline & $\begin{array}{l}\text { Obs.: Este autor rotula essas práticas como "atividades de gestão } \\
\text { de pessoas", e não como "políticas de gestão de pessoas". }\end{array}$ \\
\hline Dressler (2002) & $\begin{array}{l}\text { Recrutamento e alocação; treinamento e desenvolvimento; } \\
\text { compensação; relações trabalhistas; segurança dos empregados. }\end{array}$ \\
\hline Lawler III (2003) & $\begin{array}{l}\text { Atração e retenção; seleção; treinamento e desenvolvimento; } \\
\text { projeto de trabalho; missão, estratégias e metas; sistema de } \\
\text { recompensas; liderança. }\end{array}$ \\
\hline Mathias e Jackson (2003) & $\begin{array}{l}\text { Recrutamento e seleção; treinamento e desenvolvimento; } \\
\text { compensação; relações trabalhistas; saúde, bem-estar e segurança } \\
\text { no trabalho. }\end{array}$ \\
\hline
\end{tabular}

Quadro 2 Denominações de políticas de gestão de pessoas Fonte: Compilado de Demo (2005, p. 51-53)

Considerando-se as diversas denominações apresentadas no Quadro 2, no serviço público federal existem algumas políticas semelhantes, que na essência possuem a mesma finalidade, resguardando as devidas especificidades de um órgão público.

Para os fins desta pesquisa, as denominações de referência foram definidas pela Política Nacional de Gestão de Pessoas do Ministério do Planejamento (BRASIL, 2006): políticas de recrutamento, seleção e integração, de carreiras, de remuneração, de capacitação e desenvolvimento, de avaliação de desempenho, de relações de trabalho e de seguridade social.

Como apontam Singar e Ramsden (1972 apud DEMO, 2005, p. 54),

[...] as políticas de GP têm que constituir um documento público, acessível a todos na organização, pois elas só serão úteis e eficazes se devidamente conhecidas e compreendidas por todos. Isto significa dizer que a declaração das políticas deve ser clara, simples, objetiva e deve estar em uma linguagem acessível aos empregados.

Nessa linha de raciocínio, as políticas internas de gestão de pessoas do Instituto pesquisado estão disponibilizadas no Plano de Desenvolvimento Institucional (PDI), de 2009, descritas a seguir:

Estabelecimento de um cenário organizacional que proporcione aos servidores o seu espaço de realização através do trabalho, buscando o equilíbrio de objetivos entre a pessoa, a equipe e a Instituição; formação continuada tendo em vista o atendimento aos servidores ingressantes assim como os demais servidores da Instituição; e elaborar critérios de seleção que explicitem as concepções do IF-SC e aplicar nos editais de concursos públicos de novos servidores, até o segundo semestre de 2009.

$\mathrm{Na}$ sequência, apresentam-se as políticas de gestão de pessoas no contexto desse Instituto. 


\section{GESTÃO DE PESSOAS EM UM INSTITUTO FEDERAL DE EDUCAÇÃO, CIÊNCIA E

\subsection{Recrutamento, seleção e integração}

O processo de recrutamento de servidores para exercer suas atividades nas instituições define que tipo de instituição ela será, pois de acordo com esse pressuposto é que deverão ser escolhidos seus profissionais.

Em entrevista com o gestor do Instituto pesquisado, foram feitas perguntas a respeito dos seguintes aspectos:

a) qual o mecanismo de recrutamento e seleção utilizado no Instituto;

b) se o Instituto faz algum tipo de definição de perfis; se sim, o que norteia essa definição;

c) se a definição de perfís atende às necessidades Institucionais;

d) quais as principais dificuldades encontradas no recrutamento e seleção;

e) se é feito algum trabalho de integração dos servidores contratados.

De acordo com Art. 37, Inciso II da Constituição Federal, o recrutamento e a seleção de servidores públicos só poderão ser realizados por meio de concurso público. A legislação que regula essa atividade é o Decreto n. ${ }^{\circ}$ 6.944, de 21 de agosto de 2009, que dispõe sobre as normas para realização de concursos públicos, e a Lei n. ${ }^{\circ} 8.745$, de 9 de dezembro de 1993, que trata da contratação de professores substitutos.

Considerando o relato do gestor, o Instituto pesquisado tem como prática a definição de perfis de atuação considerando as atribuições dos cargos, bem como os ambientes organizacionais em que os servidores irão atuar, além da identificação de demandas decorrentes do PDI, do Plano Pedagógico Institucional e do Planejamento Estratégico da Instituição. Essa prática serve para auxiliar na seleção dos novos servidores mediante os conteúdos e atividades que compõem as provas realizadas e atende parcialmente às necessidades institucionais, pois há limitações legais.

Conforme o gestor, muitos candidatos aprovados no concurso público passam a conhecer a Instituição somente na hora de tomarem posse no cargo. Além disso, quando um servidor possui uma formação profissional muito diferente da atribuição do seu cargo, na maioria das vezes esse servidor fica desmotivado facilmente, pois não está atuando na área que escolheu por aptidão. Como exemplo, citou o cargo de Assistente em Administração, que possui como requisito mínimo para o ingresso apenas o Ensino Médio completo e experiência profissional de doze meses em qualquer área - um cargo ocupado, portanto, por profissionais de diversas áreas, como arquitetura, psicologia, direito, engenharias, licenciaturas, entre 


\section{GESTÃO DE PESSOAS EM UM INSTITUTO FEDERAL DE EDUCAÇÃO, CIÊNCIA E TECNOLOGIA \\ DOI: http://dx.doi.org/10.5007/1983-4535.2012v5n2p129}

outras. Pelo exposto, uma das dificuldades do serviço público está no fato de que um grande número de pessoas procura os concursos públicos buscando a estabilidade do cargo público, sem estar alinhado com as diretrizes das instituições e sem haver um entrosamento com suas formações profissionais e os cargos pretendidos.

O gestor entrevistado informou ainda que os servidores são integrados mediante o Programa de Ambientação dos Novos Servidores, que se inicia no momento da posse, quando recebem o Manual do Novo Servidor. Este contém diversas informações acerca da estrutura do Instituto, procedimentos, normas e legislação vigentes, entre outras informações. Os servidores que são recebidos de outras Instituições por meio de redistribuição também participam do Programa.

Conforme documentos apresentados pelo gestor, o Programa de Ambientação do Instituto é composto de quatro etapas:

1. ${ }^{\text {a }}$ Etapa: ambientação institucional - realizada pela equipe da Reitoria e com a participação/apresentação de todas as Pró-Reitorias e da Reitora. Tem como objetivo apresentar ao novo servidor um histórico da Instituição e informar quais as principais atividades/ações da Reitoria e qual a relação desta com as ações dos campi, além de lhe apresentar a alta direção. Essa etapa é diferenciada, considerando a carreira de cada servidor: aos servidores docentes é direcionada uma carga horária maior para a Pró-Reitoria de Ensino, e para os servidores técnico-administrativos é a Pró-Reitoria de Administração que tem uma carga horária maior.

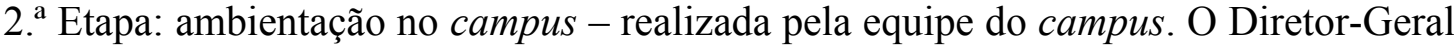
do campus e sua equipe diretiva apresentam ao servidor um histórico do campus e suas principais atividades, bem como os responsáveis por elas.

3. ${ }^{\text {a }}$ Etapa: ambientação setorial - realizada sob a coordenação da Coordenadoria de Gestão de Pessoas do campus, com o objetivo de capacitar o servidor no seu setor de trabalho. Nessa etapa, é designado um tutor para o novo servidor. É ao tutor que este poderá se reportar quando tiver alguma dúvida.

4. ${ }^{\text {a }}$ Etapa: ambientação a distância - realizada mediante ambiente virtual de aprendizagem, com o principal objetivo de apresentar ao novo servidor a legislação pertinente às suas atividades, além de documentos como estatuto, regimentos, resoluções, portarias e instruções normativas.

De acordo com o gestor, todas as etapas são obrigatórias, e a participação ou não dos novos servidores no Programa é objeto de avaliação no Programa de Avaliação de Desempenho. 


\section{GESTÃO DE PESSOAS EM UM INSTITUTO FEDERAL DE EDUCAÇÃO, CIÊNCIA E \\ TECNOLOGIA \\ DOI: http://dx.doi.org/10.5007/1983-4535.2012v5n2p129}

\subsection{Plano de carreira/remuneração}

Os planos de carreiras são documentos que instituem os caminhos que as pessoas podem percorrer em uma organização a fim de evoluírem profissionalmente. De acordo com Lacombe (2005, p. 62), “Carreira é uma série de posições exercidas por uma pessoa ao longo de sua vida profissional".

Normalmente, o que se observa nos planos de carreiras é o aproveitamento de aptidões e competências das pessoas para assumir diferentes cargos dentro da mesma instituição, havendo inclusive mudanças de atribuições e responsabilidades.

Quanto à remuneração, Demo (2005, p. 105) aponta:

[...] o sistema de recompensas aos colaboradores compreende as remunerações e os incentivos (remuneração indireta, como prêmios, opções de ações, ou ainda, a existência de um plano de carreira com chances efetivas de promoção) com fins de manter e melhorar a satisfação, a motivação e o nível de desempenho dos empregados.

O Instituto pesquisado, como uma instituição de ensino superior pública federal, tem seus servidores regidos pelo Regime Jurídico Único instituído pela Lei n. ${ }^{\circ} 8112$, de 11 de dezembro de 1990 e suas alterações. Nessa Instituição há servidores de duas carreiras: a) Magistério do Ensino Básico, Técnico e Tecnológico e b) Técnico-Administrativos em Educação (PCCTAE). As carreiras foram instituídas, respectivamente, pelas Leis n. ${ }^{\circ} 11.784$, de 22 de setembro de 2008, e 11.091, de 12 de janeiro de 2005. No entanto, considerando o Art. 37 da Constituição Federal, não é possível que um servidor público troque de cargos ao longo de sua carreira, a não ser que faça novo concurso público. Os cargos estão identificados nos anexos LXVIII da Lei n. ${ }^{\circ} 11.784 / 2008$ e II da Lei n. ${ }^{\circ} 11.091 / 2005$.

Pelas respostas obtidas pelo gestor entrevistado, percebe-se que o sistema de remuneração da instituição pesquisada é regulado por leis que são as mesmas que constituem as carreiras. A única exceção é quando um servidor ocupante de cargo efetivo é investido em função de direção, chefia e assessoramento e tem sua remuneração aumentada em razão da retribuição pelo exercício dessas funções. O gestor respondeu aos seguintes questionamentos:

a) qual o plano de carreira que rege os servidores do Instituto;

b) se um servidor contratado para um cargo específico pode exercer atividades de outro cargo;

c) o que constitui a remuneração dos servidores;

d) se o Instituto incentiva ações que contribuam para o aumento da remuneração dos seus servidores. 


\section{GESTÃO DE PESSOAS EM UM INSTITUTO FEDERAL DE EDUCAÇÃO, CIÊNCIA E TECNOLOGIA \\ DOI: http://dx.doi.org/10.5007/1983-4535.2012v5n2p129}

De acordo com o gestor, o Instituto possui programas de capacitação e desenvolvimento dos servidores, com base nas políticas internas e do governo federal. Esses programas possibilitam que os servidores recebam os benefícios da progressão por capacitação profissional e o incentivo à qualificação, de acordo com a Lei n. ${ }^{\circ} 11.091$, de 12 de janeiro de 2005.

Considerando o exposto e a narrativa do gestor, observam-se possibilidades de desvio de função no serviço público, que é caracterizado quando um servidor possui um determinado cargo com determinadas atribuições e realiza/assume atribuições e responsabilidades distintas destas. Isso pode ocorrer porque geralmente um servidor faz o concurso para um determinado cargo, mas ao longo da vida profissional e em decorrência do desenvolvimento de novas competências, vai assumindo novas responsabilidades e atribuições.

\subsection{Capacitação e desenvolvimento}

Inicialmente, é importante ressaltar que, no passado, as políticas de capacitação e desenvolvimento envolviam apenas ações de treinamento e de desenvolvimento. Não havia a preocupação com o desenvolvimento de habilidades e competências, o que é abordado com as ações de capacitação de modo mais integral.

Pacheco et al. (2009, p. 22) apontam: "O conceito de capacitação surge com a exigência de assimilação de novos conhecimentos, técnicas, atualização, desenvolvimento de competências e mudanças de atitudes traduzidas por mudanças de comportamento.”.

O Núcleo de Estudos sobre Trabalho e Educação (2000, p. 45 apud PACHECO et al., 2009) diferencia os conceitos de capacitação e treinamento:

Entende-se por capacitação o ato ou efeito de habilitar; de tornar uma pessoa capaz, possuidora de faculdades, potencial e habilidades para estar em estado de compreender e desenvolver uma determinada atividade. Não se confunde com treinamento. Nesse, o processo de ensino-aprendizagem é tomado na perspectiva de instruir, de transmitir conhecimentos e informações, de acostumar o trabalhador às tarefas que deverá assumir no seu trabalho, ou seja, de habituar, disciplinar e até de adestramento.

Nessa perspectiva, Demo (2005, p. 97) argumenta que:

Quanto ao desenvolvimento, deve-se dar ênfase à formação acadêmica do colaborador, ao estímulo à aprendizagem e atualização de conhecimentos e ao incentivo a cursos gerais não específicos para o trabalho. 


\section{GESTÃO DE PESSOAS EM UM INSTITUTO FEDERAL DE EDUCAÇÃO, CIÊNCIA E TECNOLOGIA \\ DOI: http://dx.doi.org/10.5007/1983-4535.2012v5n2p129}

Trata-se, por exemplo, da oferta de patrocínio total ou parcial para atualização e crescimento pessoal do colaborador.

Considerando-se o que foi abordado pelos autores, a Política Nacional de Desenvolvimento de Pessoal a ser implementada pelos órgãos e entidades da administração pública federal direta, autárquica e fundacional, instituída pelo Decreto n. ${ }^{\circ} 5707$, de fevereiro de 2006, que também engloba os Institutos Federais, estabelece três elementos: capacitação, treinamento regularmente instituído (eventos de capacitação e cursos de pós-graduação e estágios) e a gestão por competência.

Nesse Decreto, em seu Art. 2. ${ }^{\circ}$, Inciso I, a capacitação é concebida como o processo permanente e deliberado de aprendizagem, com o propósito de contribuir para o desenvolvimento de competências institucionais por meio do desenvolvimento de competências individuais. O treinamento regularmente instituído é qualquer ação de capacitação contemplada no Art. 2. ${ }^{\circ}$, inciso III, ou seja, eventos de capacitação tais como cursos presenciais e a distância, aprendizagem em serviço, grupos formais de estudos, intercâmbios, estágios, seminários e congressos, que contribuam para o desenvolvimento do servidor e que atendam aos interesses da administração pública federal direta, autárquica e fundacional. No treinamento regularmente instituído, incluem-se também os programas de mestrado e doutorado, pós-doutorado, especialização e estágio. A gestão por competência, o terceiro elemento, segundo o Art. 2. ${ }^{\circ}$, inciso II do Decreto, é a gestão de capacitação orientada para o desenvolvimento do conjunto de conhecimentos, habilidades e atitudes necessárias ao desempenho das funções dos servidores, visando ao alcance dos objetivos da Instituição.

Diante das nomenclaturas e definições desses três elementos, é possível perceber que nem sempre esses conceitos correspondem ao que alguns autores definem como capacitação, treinamento e desenvolvimento. Porém, esta política nacional de desenvolvimento de pessoal busca contemplar de certa forma esses conceitos. Uma amostra disso são as treze diretrizes do referido Decreto, das quais se destacam as seguintes: incentivar e apoiar o servidor público em suas iniciativas de capacitação voltadas para o desenvolvimento das competências institucionais e individuais; assegurar o acesso dos servidores a eventos de capacitação interna ou externamente ao seu local de trabalho; promover a capacitação gerencial do servidor e sua qualificação para o exercício de atividades de direção e assessoramento; incentivar e apoiar iniciativas de capacitação promovidas pelas próprias instituições, mediante o aproveitamento de habilidades e conhecimentos de servidores do seu próprio quadro de pessoal; estimular a 


\section{GESTÃO DE PESSOAS EM UM INSTITUTO FEDERAL DE EDUCAÇÃO, CIÊNCIA E TECNOLOGIA \\ DOI: http://dx.doi.org/10.5007/1983-4535.2012v5n2p129}

participação do servidor em ações de educação continuada, entendida como a oferta regular de cursos para o aprimoramento profissional, ao longo de sua vida funcional.

É importante evidenciar os três instrumentos desta Política Nacional de Desenvolvimento de Pessoal: o plano anual de capacitação, o relatório de execução do plano anual de capacitação e o sistema de gestão por competência.

Frente a uma intenção mais ampla dessa política nacional, ressalta-se o desenvolvimento como elemento-chave, o qual vem fortalecendo a necessidade de desenvolver os servidores públicos, e não só treiná-los e capacitá-los. Segundo Demo (2005, p. 92),

[...] é interessante esclarecer que o desenvolvimento é mais abrangente que o treinamento específico para o trabalho e a tarefa. Mais que treinar os colaboradores em habilidades específicas para melhorar seu desempenho na função de trabalho, a organização deve primar pelo seu constante crescimento pessoal e profissional. A ação de desenvolver já dá ideia de continuidade e a atualização de conhecimento é imprescindível nos dias de hoje.

Após essa breve contextualização, são identificadas a seguir as políticas de gestão de pessoas no Instituto pesquisado, conforme o planejamento institucional para 2010: envolver os campi do Instituto em um programa integrado de capacitação, estimulando o crescimento profissional e pessoal dos servidores; possibilitar o desenvolvimento integral dos servidores, atentando para o atendimento das necessidades da Instituição; estimular e apoiar os profissionais que buscam o autodesenvolvimento, criando situações que venham a facilitar essa busca.

Conhecendo-se essas políticas pelos documentos institucionais e com base na política nacional de pessoal instituída pelo Decreto n. ${ }^{\circ}$ 5707, de fevereiro de 2006 (BRASIL, 2006), foi questionado junto ao gestor do Instituto:

a) se o Instituto tem aplicado a política e as diretrizes para a capacitação e o desenvolvimento de pessoal por meio do Decreto n. ${ }^{\circ}$ 5707, de fevereiro de 2006;

b) se a gestão de capacitação por competência, exigência desse Decreto, já é uma realidade nesse Instituto;

c) se essa Instituição segue as diretrizes da Política Nacional de Desenvolvimento de Pessoal;

d) como avalia a aplicação dessas diretrizes;

e) de forma geral, como avaliaria os avanços e dificuldades dessa Instituição em relação à aplicação da política e diretrizes de desenvolvimento de pessoal instituído pelo Decreto mencionado. 


\section{GESTÃO DE PESSOAS EM UM INSTITUTO FEDERAL DE EDUCAÇÃO, CIÊNCIA E TECNOLOGIA \\ DOI: http://dx.doi.org/10.5007/1983-4535.2012v5n2p129}

Quanto à primeira pergunta, o gestor respondeu que o Instituto tem aplicado a política e as diretrizes para a capacitação e o desenvolvimento de pessoal por meio do Decreto $n .^{\circ}$ 5707, de fevereiro de 2006, mediante a implantação gradativa da gestão por competências e dos programas de capacitação e desenvolvimento pessoal e profissional dos seus servidores.

No que se refere à pergunta $b$, o gestor afirmou que a gestão de capacitação por competência, exigência do Decreto, já é uma realidade no Instituto a partir da avaliação de desempenho realizada por sistema informatizado, que gera relatórios nos quais podem-se observar as necessidades de capacitação, definindo níveis de priorização para o desenvolvimento das competências. Dessa forma, a gestão de capacitação por competências estará totalmente implantada, e, portanto, o processo para que ela se torne realidade já está em andamento.

No tocante às questões $\mathrm{c} e \mathrm{~d}$, o gestor disse que o Instituto segue as diretrizes da Política Nacional de Desenvolvimento de Pessoal e avalia a aplicação dessas diretrizes como norteadora das ações de capacitação e desenvolvimento dos servidores. No entanto, nem todas as diretrizes são contempladas, principalmente no que se refere à mensuração dos resultados das ações de capacitação e a utilização dessa avaliação como requisito para os servidores assumirem funções de direção e assessoramento.

Com relação ao último questionamento, o gestor informou que os principais avanços foram a implantação dos conceitos de gestão por competências e a criação de um departamento com a finalidade específica de cuidar do desenvolvimento dos servidores. Entre as principais dificuldades, apontou a dotação orçamentária, geralmente restrita para dar conta de atender a todas as demandas existentes numa instituição do porte do Instituto. Apontou ainda como dificuldade a cultura organizacional, que precisa ser trabalhada para que a avaliação de desempenho possa subsidiar cada vez mais os programas de capacitação e desenvolvimento.

O Instituto pesquisado, em fevereiro de 2009, criou em sua estrutura organizacional o Departamento de Seleção e Desenvolvimento de Pessoas, demonstrando a valorização do servidor e do desenvolvimento deste na sua carreira, uma das finalidades apontadas no Decreto n. ${ }^{\circ}$ 5707, de fevereiro de 2006, Art. $1 .^{\circ}$, inciso II.

O mesmo ocorre com a criação de uma Coordenação de Capacitação nesse departamento, que tem como objetivo desenvolver políticas de capacitação e desenvolvimento 


\section{GESTÃO DE PESSOAS EM UM INSTITUTO FEDERAL DE EDUCAÇÃO, CIÊNCIA E TECNOLOGIA \\ DOI: http://dx.doi.org/10.5007/1983-4535.2012v5n2p129}

permanente dos servidores da Instituição, viabilizando ações de formação e educação continuada. As ações devem ser pautadas na busca pela ampliação do conhecimento e na geração de ideias inovadoras, visando a desenvolver a criatividade, a autonomia, a ação reflexiva e a flexibilidade, tendo como base as necessidades formativas dos servidores e, fundamentalmente, da Instituição. Essa Coordenação leva em conta as demandas gerais e setoriais da Instituição, fundamentando-se em diversas fontes de informação (avaliação de desempenho dos servidores, levantamento de necessidades de capacitação dos campi, redes de feedback, análise da direção, relatórios da avaliação institucional, entre outros), que serão base para o planejamento de ações de capacitação e desenvolvimento humano.

O gestor entrevistado reforçou que a Instituição vem gradativamente aplicando as diretrizes para o desenvolvimento de pessoal. No ano de 2007, a Instituição promoveu o mapeamento das competências individuais dos servidores e as competências institucionais, e esse mapeamento foi utilizado como subsídio para desenvolverem-se os formulários do programa de avaliação de desempenho dos servidores. A partir do Decreto n. ${ }^{\circ}$ 5707, de fevereiro de 2006, também foram intensificadas as atuações dos próprios servidores como multiplicadores das ações de capacitação, de modo a valorizar as suas competências pessoais. Essa ação tem se mostrado uma oportunidade para minimizarem-se os custos nas capacitações, racionalizando os gastos públicos, como prega o Art. 1. ${ }^{\circ}$, inciso V, do Decreto n. ${ }^{\circ} 5707$.

Com base no planejamento e no relatório anual de 2010 da Coordenação de Capacitação, identificou-se que o Instituto realiza o plano anual de capacitação e apresenta o relatório de execução desse plano, instrumentos estabelecidos no Decreto n. 5707.

\subsection{Avaliação de desempenho}

A avaliação de desempenho é uma importante ferramenta de gestão de pessoas, que tem como objetivo contribuir para o desenvolvimento dos indivíduos, das equipes de trabalho e da instituição como um todo. O processo é uma análise sistemática do desempenho do profissional em função das atividades que realiza, das suas metas, dos resultados alcançados e de seu potencial de desenvolvimento.

As organizações têm buscado novos métodos, mais participativos, de avaliação, a fim de dirigir o esforço das pessoas para objetivos e metas institucionais e individuais. Enquanto nos métodos tradicionais a avaliação funcionava como um fim, na gestão de 


\section{GESTÃO DE PESSOAS EM UM INSTITUTO FEDERAL DE EDUCAÇÃO, CIÊNCIA E TECNOLOGIA \\ DOI: http://dx.doi.org/10.5007/1983-4535.2012v5n2p129}

pessoas entra-se em consenso sobre desempenho, metas e padrões. A tendência atual é que a avaliação seja um importante meio para melhorar e impulsionar o comportamento das pessoas, oferecendo uma visão crítica constante, sendo útil para o retorno de informações sobre pontos fortes e fracos e apresentando as adequações necessárias para a eficácia e construção da carreira.

O resultado final da avaliação de desempenho deverá identificar as necessidades de melhoria, de qualificação e determinação de potencial, e a gestão de remuneração servirá como base para a elaboração de um plano de ações tanto da Instituição quanto dos servidores. Com o resultado, o avaliado poderá partir para a correção e reajuste de seu desempenho, aumentando sua eficácia pessoal. Para a Instituição, o processo contribui na retenção de talentos, na formação de uma cultura de aprendizado permanente, no aumento da motivação e da produtividade.

Girardi (2008, p. 45) destaca que as formas de avaliação mais comuns são: “[...] a autoavaliação feita pela própria pessoa e a avaliação $360^{\circ}$ efetuada pelo gerente, pelo conjunto pessoa/gerente, gerente/equipe, pela área de RH ou pela comissão de avaliação.”.

No serviço público, a Lei n. ${ }^{\circ} 11.784$, de 22 de setembro de 2008, instituiu a sistemática de avaliação de desempenho dos servidores de cargos de provimento efetivo e em comissão da administração pública federal, direta, autárquica e fundacional, com o objetivo de promover a melhoria da qualificação dos serviços públicos e de subsidiar a política de gestão de pessoas, principalmente quanto à capacitação, desenvolvimento no cargo ou na carreira, remuneração e movimentação de pessoal. A Lei define como avaliação de desempenho o monitoramento sistemático e contínuo da atuação individual do servidor e a atuação institucional dos órgãos e das entidades (BRASIL, 2008).

Segundo a Lei, a avaliação de desempenho individual deverá refletir as competências do servidor no desempenho individual das tarefas e atividades a ele atribuídas. Já a avaliação institucional deverá refletir a contribuição da equipe de trabalho no cumprimento das metas e os resultados alcançados pela Instituição. Nesta pesquisa, os gestores foram abordados somente quanto à avaliação de desempenho individual.

Como esclarece Franco (2002, p. 95), “[...] o conceito de competência mudou completamente nos últimos anos. Estamos agora em condições de compreendê-lo melhor: é competente quem tem mérito, unindo saber, habilidades técnicas e formas de ser e agir [...] capazes de distingui-lo da maioria". 


\section{GESTÃO DE PESSOAS EM UM INSTITUTO FEDERAL DE EDUCAÇÃO, CIÊNCIA E TECNOLOGIA \\ DOI: http://dx.doi.org/10.5007/1983-4535.2012v5n2p129}

Os servidores poderão ser avaliados por autoavaliação, pela chefia imediata e pelos demais integrantes da equipe de trabalho. Ainda de acordo com a Lei, os servidores ocupantes de cargos em comissão ou função de confiança poderão ser avaliados por autoavaliação, pela chefia imediata e pela equipe de trabalho subordinada à chefia imediata. $\mathrm{O}$ servidor que obtiver avaliação de desempenho individual inferir a $50 \%$ da pontuação máxima prevista será submetido a processo de capacitação ou de análise da adequação funcional.

O ciclo da avaliação de desempenho é de doze meses, mas o primeiro ciclo poderá ter duração inferior. O ciclo compreenderá a publicação das metas globais, o estabelecimento de compromissos de desempenho individual e institucional, o acompanhamento do desempenho individual, a avaliação parcial dos resultados, a apuração final das pontuações, a publicação do resultado e o retorno aos avaliados.

A Lei também estabelece que seja composta nos órgãos uma Comissão de Acompanhamento para julgar, em última instância, os recursos aos resultados das avaliações individuais.

Além dessa Lei, o Programa de Avaliação de Desempenho, contido no Plano de Desenvolvimento dos Integrantes do Plano de Carreira dos Servidores TécnicoAdministrativos em Educação (PDIC), elaborado a partir do Decreto 5.825, de 29 de junho de 2006, também estabeleceu critérios para a análise da atuação profissional dos servidores, da qualidade dos resultados e da competência demonstrada no exercício do cargo, observando os princípios e diretrizes estabelecidos no Art. $3 .^{\circ}$ da Lei n. ${ }^{\circ} 11.091$, de 12 de janeiro de 2005.

Para identificar as políticas de avaliação de desempenho do Instituto, foram apresentadas as seguintes questões ao gestor:

a) se é feita a avaliação de desempenho; em caso afirmativo, se está sistematizada;

b) como se desenvolve a avaliação de desempenho nos campi;

c) se a gestão por competências é contemplada na avaliação de desempenho;

d) como o servidor fica sabendo do resultado da sua avaliação;

e) se os servidores são avaliados pela comunidade;

f) o que é feito com o resultado do processo da avaliação de desempenho.

A avaliação de desempenho dos servidores do Instituto pesquisado é normatizada por resolução de órgão colegiado. Segundo o gestor, o Programa de Avaliação de Desempenho foi revisado e reelaborado para atender ao Decreto n. ${ }^{\circ}$ 5.707, de 23 de fevereiro de 2006, que 


\section{GESTÃO DE PESSOAS EM UM INSTITUTO FEDERAL DE EDUCAÇÃO, CIÊNCIA E TECNOLOGIA \\ DOI: http://dx.doi.org/10.5007/1983-4535.2012v5n2p129}

determinou que o Sistema de Gestão por Competências deve ser um dos instrumentos da Política Nacional de Desenvolvimento de Pessoal.

De acordo com análise documental, o Programa tem como objetivos gerais o desenvolvimento dos servidores, a aferição de mérito para progressão funcional, a melhoria do funcionamento dos setores e o consequente desenvolvimento da Instituição, pressupondo que todo servidor tem capacidade de aprender e desenvolver diversas competências.

O Programa de Avaliação de Desempenho pesquisado tem como objetivos:

a) analisar a contribuição de cada servidor na execução dos objetivos do seu setor e da Instituição;

b) contribuir para o planejamento da capacitação pela área de gestão;

c) identificar potencialidades e carências profissionais;

d) diagnosticar os aspectos relacionados às condições de trabalho coletivo e individual que facilitam ou dificultam o desempenho, visando ao aprimoramento dos recursos pessoais e materiais e à superação das dificuldades encontradas;

e) levantar subsídios para a elaboração de planos de ação, buscando aperfeiçoar os desempenhos diagnosticados como não satisfatórios;

f) aferir o mérito para progressão funcional.

No caso do Instituto Federal pesquisado, o setor do Instituto denominado Coordenadoria de Capacitação do Departamento de Seleção e Desenvolvimento de Pessoas efetua, como marco inicial do processo de avaliação de desempenho, o treinamento dos servidores das Coordenadorias de Gestão de Pessoas dos campi e equipes de apoio que irão treinar os avaliadores. Essas coordenadorias e os avaliadores realizam, então, um trabalho de sensibilização do servidor a ser avaliado, bem como dos avaliadores.

De acordo com o gestor entrevistado, com o objetivo de alinhar a avaliação de desempenho com a política de gestão por competências, os formulários foram constituídos considerando-se a mensuração de competências conceituais: conhecimentos e teorias que embasam a prática profissional; competências técnicas: domínio de métodos e ferramentas de determinada área ou atividade profissional; competências interpessoais: comunicação e interação de forma positiva. Atitudes e valores pessoais também são considerados no momento da avaliação.

Segundo o gestor, a avaliação de desempenho é realizada no mês de setembro de cada ano, mediante um sistema informatizado em que o servidor avaliado faz seu login e efetua sua autoavaliação e a avaliação de sua chefia e subordinados (quando os houver). Em novembro, o avaliado tem acesso à sua avaliação no mesmo sistema. Após a divulgação do resultado, a 


\section{GESTÃO DE PESSOAS EM UM INSTITUTO FEDERAL DE EDUCAÇÃO, CIÊNCIA E TECNOLOGIA \\ DOI: http://dx.doi.org/10.5007/1983-4535.2012v5n2p129}

chefia imediata realiza uma entrevista com o servidor para comunicar o resultado e para construírem juntos um plano de ação para o desenvolvimento do servidor. Para o gestor, o Programa traz a sugestão de vinte cursos que poderão ser escolhidos pela chefia e o servidor. Há um formulário padrão para ser preenchido nessa entrevista, no qual o servidor dá ciência da avaliação.

Caso discorde do resultado da avaliação, em quinze dias o servidor deve apresentar recurso à Direção-Geral do Campus/Pró-Reitoria, que o encaminha à Comissão Permanente de Avaliação de Desempenho dos Servidores (CPADS). O processo é instruído, a argumentação do avaliado é analisada e a ele é garantida ampla defesa. A CPADS emite parecer no processo e o encaminha para o órgão colegiado.

Conforme relato do gestor, após o término do processo podem ser emitidos relatórios qualitativos e quantitativos, que servem como subsídio para a identificação das demandas por ações de capacitação e as principais competências a serem desenvolvidas. Além disso, poderão ser identificados, mediante a identificação das competências que apresentaram melhores resultados, os talentos humanos potenciais da Instituição.

\subsection{Relações de trabalho}

Entende-se que a política de relações de trabalho é semelhante à política de envolvimento. Demo (2005, p. 84) a define da seguinte maneira: "Esta política engloba as práticas de comunicação organizacional, de participação, de relacionamento e, ainda, de reconhecimento às contribuições dos colaboradores".

Considerando as perspectivas de comunicação, participação, relacionamento e reconhecimento, questionou-se ao gestor quais eram as práticas adotadas pela Instituição. Para ele, a comunicação ocorre por meio da utilização de correio eletrônico, intranet, boletim eletrônico semanal, jornal impresso, mídias sociais, murais, reuniões formais e ampliadas e ouvidoria. Na Reitoria há também uma agenda eletrônica com todos os eventos institucionais, disponível no desktop dos computadores.

Dessler (2002 apud DEMO, 2005, p. 90) define "os programas de participação dos empregados como qualquer programa formal que permita a eles participar da formulação de importantes decisões de trabalho e da supervisão total ou parcial de suas atividades e funções (autonomia)". 


\section{GESTÃO DE PESSOAS EM UM INSTITUTO FEDERAL DE EDUCAÇÃO, CIÊNCIA E TECNOLOGIA \\ DOI: http://dx.doi.org/10.5007/1983-4535.2012v5n2p129}

Segundo Silva et al. (2007), em uma gestão educacional verdadeiramente democrática, é fundamental ouvir a opinião das pessoas. Considerando essa afirmação, ressalta-se que no Instituto pesquisado há diversas formas de participação dos diversos atores da comunidade.

Em análise documental, identificou-se que o Art. 7 do Capítulo III do Estatuto da Instituição define como parte de sua estrutura básica os órgãos colegiados: Conselho Superior e Colégio de Dirigentes. O Conselho Superior é composto por representantes dos docentes, dos estudantes, dos servidores técnico-administrativos, dos egressos da Instituição, da sociedade civil, do Ministério da Educação e do Colégio de Dirigentes. Assegura-se a representação paritária dos segmentos que compõem a comunidade acadêmica.

Ainda como forma de participação da comunidade na gestão da Instituição, no Regimento Interno estão definidos como órgãos de assessoramento: Colegiado de Desenvolvimento de Pessoas; Colegiado de Ensino, Pesquisa e Extensão; Comissão Interna de Supervisão do Plano de Carreira dos Cargos Técnico-Administrativos em Educação; Comissão Permanente de Pessoal Docente; Comissão Própria de Avaliação.

Salienta-se na entrevista que todos os representantes dos colegiados e conselhos, bem como ocupantes de cargos de chefia e funções gratificadas dos campi, são escolhidos por meio de processo eleitoral. Além disso, conforme o gestor, o próprio sistema de construção do estatuto e do regimento interno foi executado de forma participativa, mediante audiências públicas com toda a comunidade interna.

Outras formas de participação da comunidade acontecem na construção do Plano de Desenvolvimento Institucional (PDI), do Plano Político Institucional (PPI) e do Planejamento Estratégico.

Segundo o gestor, o sistema de gestão de pessoas da Instituição tem uma aplicação que informa os aniversariantes do dia. A Reitora da Instituição encaminha e-mail pessoal a cada aniversariante, estimulando a confraternização dos momentos especiais. Além disso, há a cultura de comemorar as datas especiais, como dia da mulher, dia das mães, dia do servidor público, entre outros.

O gestor informou que práticas bem sucedidas geralmente são reconhecidas pelos meios de comunicação da Instituição, evidenciando-se dessa forma os servidores envolvidos. A Instituição também possui uma Comissão Permanente para Preparação para a Aposentadoria, que trabalha com ações de reconhecimento e valorização dos servidores pela contribuição que deram à Instituição. 


\title{
GESTÃO DE PESSOAS EM UM INSTITUTO FEDERAL DE EDUCAÇÃO, CIÊNCIA E

\subsection{Seguridade social}

A seguridade social está prevista pela Carta Magna (BRASIL, 1988) em seu Artigo 194 e seguintes:

\begin{abstract}
A seguridade social compreende um conjunto integrado de ações de iniciativa dos poderes públicos e da sociedade, destinadas a assegurar os direitos relativos à saúde, à previdência e à assistência social.

Parágrafo único. Compete ao poder público, nos termos da lei, organizar a seguridade social.
\end{abstract}

A Lei n. ${ }^{\circ} 8.112$, de 11 de dezembro de 1990, em seu Artigo 183 e seguintes, elenca os benefícios colocados à disposição do servidor consoantes à seguridade social, tais como aposentadoria, auxílio-natalidade, salário-família, licença para tratamento de saúde, licença à gestante, à adotante e licença-paternidade, licença por acidente em serviço, assistência à saúde e garantia de condições individuais e ambientais de trabalho satisfatórias. Quanto ao dependente, elencam-se os seguintes benefícios: pensão vitalícia e temporária, auxílio-funeral, auxílio-reclusão e assistência à saúde.

O governo federal, em sua Política Nacional de Gestão de Pessoas, destaca a seguridade social em quatro áreas: saúde ocupacional, saúde suplementar, previdência e benefícios não salariais.

Percebe-se que o Estado vem buscando regulamentar a seguridade social do servidor público civil federal no âmbito da União mediante a universalização e padronização do atendimento e dos procedimentos para implantação do sistema de saúde ocupacional, inserindo novas abordagens, como o assédio moral e a democratização e universalização do acesso à saúde suplementar com a contrapartida do governo federal.

A saúde suplementar está regulamentada pela Portaria Normativa n. ${ }^{\circ}$ 3, de 30 de julho de 2009, do Ministério do Planejamento, Orçamento e Gestão. Essa Portaria estabelece orientações aos órgãos e entidades do Sistema de Pessoal Civil da Administração Federal (SIPEC), sobre a assistência à saúde suplementar do servidor ativo, inativo, seus dependentes e pensionistas. A assistência à saúde na forma suplementar, de acordo com essa Portaria,

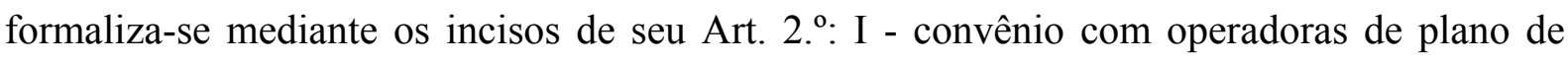
assistência à saúde, organizadas na modalidade de autogestão; II - contrato com operadoras de plano de assistência à saúde, observado o disposto na Lei n. ${ }^{\circ}$ 8.666, de 21 de junho de 1993; III - serviço prestado diretamente pelo órgão ou entidade; ou IV - auxílio de caráter 


\section{GESTÃO DE PESSOAS EM UM INSTITUTO FEDERAL DE EDUCAÇÃO, CIÊNCIA E TECNOLOGIA \\ DOI: http://dx.doi.org/10.5007/1983-4535.2012v5n2p129}

indenizatório, por meio de ressarcimento, quando não adotado pelo órgão ou entidade do SIPEC o contido no inciso II deste artigo.

Buscando conhecer as políticas de seguridade social em um Instituto Federal e considerando as políticas públicas do governo federal, perguntou-se ao gestor entrevistado:

a) como é feita pelo Instituto a análise de doenças e acidentes relacionados ao trabalho;

b) como ocorre o monitoramento e controle de saúde ocupacional dos servidores;

c) de que forma ocorrem os pareceres médicos sobre saúde dos servidores;

d) como o Instituto trata das doenças de ambulatório e de DST/AIDS dos seus servidores.

Como resposta, o gestor afirmou que recorrem ao Subsistema Integrado de Atenção à Saúde do Servidor Público Federal (SIASS) para encaminhamento dessas questões. Foram realizados ainda os seguintes questionamentos, para os quais o gestor afirmou não haver ações no âmbito da Instituição:

a) como o Instituto monitora e planeja o controle de riscos;

b) se existem treinamentos na área de segurança do trabalho;

c) se existem algum monitoramento e controle de saúde bucal dos servidores;

d) se o Instituto incentiva a informação preventiva; se sim, de que forma; se não, por quê;

e) de que forma o Instituto capacita sua equipe de trabalho que trata sobre segurança no trabalho;

f) como é feito o trabalho de prevenção a acidentes de trabalho.

Questionado sobre quem elabora e de que forma são feitos os laudos periciais do Instituto e quais são os critérios adotados, o gestor informou que os laudos eram realizados por uma empresa contratada por processo licitatório.

Indagado ainda de que forma o Instituto trata a prevenção de incêndio com os seus servidores e se existe algum trabalho de conscientização e prevenção, o entrevistado respondeu que foram realizadas palestras com o Corpo de Bombeiros das cidades dos campi, com os seguintes temas: prevenção contra incêndio, teoria básica do fogo, classificação dos combustíveis, métodos de extinção de incêndio, agentes extintores e sua utilização e técnicas de combate a incêndio.

O SIASS, citado pelo entrevistado, foi regulamentado pelo Decreto n. ${ }^{\circ} 6.833$, de 29 de abril de 2009. Por meio do SIASS, o Estado pretende diminuir os custos, unificar e 


\section{GESTÃO DE PESSOAS EM UM INSTITUTO FEDERAL DE EDUCAÇÃO, CIÊNCIA E TECNOLOGIA \\ DOI: http://dx.doi.org/10.5007/1983-4535.2012v5n2p129}

uniformizar o atendimento aos seus servidores na área de saúde e assistência social (SIASS, 2011).

A Política de Saúde e Assistência Social que é prestada pelo SIASS contempla o acompanhamento e proteção da saúde dos servidores, a vigilância dos fatores de risco, presentes nos ambiente e condições de trabalho e dos agravos à saúde, a prestação da assistência, do tratamento e da reabilitação, além da concessão e acesso a benefícios e facilidades, com o objetivo de propiciar as melhores condições de saúde e qualidade de vida para os servidores públicos federais.

O SIASS, vinculado às políticas de saúde estatal e considerado uma conquista dos servidores públicos federais, busca minimizar os agravos à saúde e à assistência social dos servidores públicos federais e às condições de trabalho dos servidores regidos pelo Regime Jurídico Único (RJU), que não eram contemplados com as mesmas garantias dos trabalhadores regidos pela Consolidação das Leis do Trabalho (CLT), como, por exemplo, a obrigatoriedade da constituição de Comissões Internas de Prevenção de Acidentes e dos Serviços de Segurança e Medicina do Trabalho.

Além de uma política de saúde eficiente e de uma previdência bem estruturada, é fundamental que os órgãos federais contemplem seus trabalhadores com benefícios não salariais. Benefícios não salariais podem ser compreendidos como aqueles oferecidos aos trabalhadores além do pagamento salarial; exemplos são o acesso permanente a cuidados médicos, vale-refeição com poder aquisitivo de acordo com o mercado, bolsas de estudo, incentivo à capacitação, entre outros. Estes são benefícios que influenciam diretamente na saúde física e mental dos servidores.

\section{A HISTÓRIA DOS INSTITUTOS FEDERAIS DE EDUCAÇÃO, CIÊNCIA E TECNOLOGIA}

A Lei n. ${ }^{\circ}$ 11.892, de 29 de dezembro de 2008, implantou 38 Institutos Federais de Educação, Ciência e Tecnologia. Os Institutos Federais são instituições de educação básica, profissional e superior distribuídas por vários campi, vinculadas ao Ministério da Educação (MEC) por meio da Secretaria de Educação Profissional e Tecnológica (SETEC), integrando a Rede Federal de Educação Profissional. Fazem parte da Rede, além dos 38 Institutos, o CEFET do Rio de Janeiro, o CEFET de Minas Gerais, 24 Escolas Técnicas vinculadas às 


\section{GESTÃO DE PESSOAS EM UM INSTITUTO FEDERAL DE EDUCAÇÃO, CIÊNCIA E TECNOLOGIA \\ DOI: http://dx.doi.org/10.5007/1983-4535.2012v5n2p129}

Universidades Federais, a Universidade Tecnológica Federal do Paraná (UTFPR) e o Colégio Pedro II do Rio de Janeiro.

A origem dos Institutos Federais de Educação, Ciência e Tecnologia remonta ao Decreto n. ${ }^{\circ}$ 7.566, de 23 de setembro de 1909, pelo qual foram criadas dezenove escolas de Aprendizes e Artífices, instituições voltadas para a educação profissional das classes mais pobres. Em 1937, estas passaram a ser denominadas Liceus Profissionais, e em 1949, Escolas Industriais. No final da década de 1950, os Liceus foram transformados em Escolas Técnicas, todas voltadas para o ensino técnico e profissionalizante. Nas décadas de 1970, 1980 e 1990, acompanhando as profundas mudanças econômicas e sociais, as Escolas Técnicas, gradativamente, passaram a denominar-se Centros Federais de Educação Tecnológica - os CEFETs -, e muitos passaram a ofertar ensino superior (ALMEIDA, 2010).

Segundo Pacheco (2010), a proposta dos Institutos Federais aponta para uma instituição identificada e comprometida com a sociedade, sintonizada com as demandas sociais, econômicas e culturais, de forma local e regional, a fim de promover a oferta educativa pela construção de itinerários de formação que permitam a integração de diferentes níveis de educação profissional e tecnológica no seu projeto pedagógico. Os Institutos podem ofertar cursos de formação inicial e continuada, cursos técnicos de nível médio, cursos tecnológicos, licenciatura e pós-graduação, democratizando e ampliando a acesso ao ensino gratuito público.

\section{PROCEDIMENTOS METODOLÓGICOS}

A metodologia utilizada neste estudo fundamentou-se na pesquisa aplicada. Para Vergara (2007), a pesquisa aplicada é fundamentalmente motivada pela necessidade de resolver problemas concretos, tendo, pois, uma finalidade prática. Mattar (1999) relata que, nesse tipo de análise, estão envolvidos indagações na formulação de política ou planejamento.

Recorreu-se também à pesquisa descritiva. Segundo Gil (2007), a pesquisa descritiva tem como objetivo primordial a descrição das características de uma determinada população, ou fenômeno, ou, então, o estabelecimento de relações entre variáveis.

A pesquisa caracteriza-se ainda como um estudo de caso, tendo como referência um Instituto Federal de Educação, Ciência e Tecnologia. Realizou-se assim uma pesquisa bibliográfica e documental com tratamento qualitativo e entrevista semiestruturada com o gestor Chefe do Departamento de Seleção e Desenvolvimento de Pessoas. A escolha do 


\section{GESTÃO DE PESSOAS EM UM INSTITUTO FEDERAL DE EDUCAÇÃO, CIÊNCIA E TECNOLOGIA \\ DOI: http://dx.doi.org/10.5007/1983-4535.2012v5n2p129}

entrevistado justifica-se pelo fato de, no departamento citado, serem criadas, fomentadas e, na maioria das vezes, executadas as políticas de gestão de pessoas abordadas neste estudo.

Como resultado, buscou-se identificar oportunidades de melhorias nas políticas de gestão de pessoas em um Instituto, relacionadas às políticas públicas do governo federal.

\section{ANÁLISE E DISCUSSÃO DOS RESULTADOS}

Considerando a pesquisa realizada neste estudo e as entrevistas realizadas com o gestor do Instituto, ressalta-se que esta pesquisa restringiu-se a estudar seis políticas de gestão de pessoas: 1) recrutamento, seleção e integração; 2) plano de carreiras e remuneração; 3) plano de capacitação e desenvolvimento; 4) avaliação de desempenho; 5) relações de trabalho; 6) seguridade social. A pesquisa buscou identificar e analisar as políticas de gestão de pessoas e discutir os resultados, conforme segue.

Como resultado da pesquisa, avalia-se que a política de recrutamento e de seleção está limitada à legislação pertinente, o que dificulta a definição dos perfis desejados, bem como a seleção de novos servidores alinhada à gestão por competências.

Observou-se que, considerando o cenário que compõe as contratações no serviço público, o trabalho de integração dos novos servidores é de suma importância a fim de situar o novo servidor e sanar as dificuldades já expostas decorrentes das contratações de servidores no serviço público. Define-se a integração como uma prática estratégica das instituições, pois um servidor bem integrado poderá ser mais produtivo em um menor espaço de tempo, além de fortalecer a imagem da Instituição, tanto para o novo servidor quanto externamente. Essa prática contribui para que o servidor caminhe rumo aos objetivos e diretrizes estabelecidos pela filosofia da Instituição. Salienta-se que o programa de ambientação implantado no Instituto trouxe mudanças e atende aos objetivos da política interna.

Quanto à política de carreira e remuneração, na Instituição pesquisada o sistema de remuneração é regulado por leis, que são as mesmas que constituem as carreiras, exceto quando o servidor ocupante de cargo efetivo é investido em função de direção, chefia e assessoramento e tem sua remuneração aumentada em razão do exercício dessas funções.

Destaca-se ainda que, de acordo com os documentos apresentados e informações repassadas pelo gestor entrevistado, é possível afirmar que no serviço público federal há planos de salários e não de carreira, pois o servidor muda seu padrão de vencimento por meio de progressões salariais dentro do mesmo cargo. 


\section{GESTÃO DE PESSOAS EM UM INSTITUTO FEDERAL DE EDUCAÇÃO, CIÊNCIA E TECNOLOGIA \\ DOI: http://dx.doi.org/10.5007/1983-4535.2012v5n2p129}

Em referência à política de capacitação e desenvolvimento, considera-se que a Instituição vem buscando um nível satisfatório, conforme verificado na entrevista, nos documentos disponibilizados, com referência às orientações do Decreto n. $^{0} 5.707$, de fevereiro de 2006, que estabelece a Política Nacional de Desenvolvimento de Pessoal, e nas suas próprias políticas internas de capacitação e desenvolvimento. Após a entrevista, e relacionando-a à Política Nacional de Desenvolvimento de Pessoal instituída pelo Decreto, é possível perceber a busca desse Instituto em atender à Política Nacional e às suas próprias políticas. Um dos exemplos são as ações identificadas como necessárias e que buscaram efetivar as políticas de desenvolvimento e capacitação do Instituto que estão definidas no Planejamento de 2010, alinhadas de certa forma com algumas das exigências do referido Decreto:

[...] realização de diagnóstico de necessidades (levantamento de necessidades de treinamento - LNT, avaliação de desempenho e solicitações da direção); desenvolvimento de propostas de capacitação para os servidores, em parceria com diversos setores da Instituição; realização de ações de capacitação descentralizadas a serem realizadas pelas coordenações de Gestão de Pessoas dos Campi; avaliação e acompanhamento das ações de capacitação realizada (internas e externas), verificando o atendimento dos objetivos e metas propostas; organização de planilhas de controle interno dos cursos realizados pela Instituição (na DGP e nos campi), visando à alimentação dos dados para emissão de certificados e eventuais consultas; emissão dos certificados realizados exclusivamente pela DGP, após análise das ações (por intermédio de avaliações elaboradas e enviadas pelas Coordenações de Gestão de Pessoas das Unidades).

Destaca-se que o Instituto pesquisado busca também aperfeiçoar o processo de mensuração dos resultados das ações de capacitação, porém essa é uma característica que os órgãos públicos ainda procuram potencializar. Outro destaque é a gestão de capacitação por competências, que o Instituto já vem realizando, e que se mostra um grande desafio em uma instituição pública.

No que tange à política de avaliação de desempenho, contemplada pela Instituição, esta alinha-se com as políticas de gestão de pessoas constantes no Decreto n. ${ }^{\text {o }}$ 5.707, valorizando a gestão por competências. Além disso, utiliza o resultado da avaliação como ferramenta de gestão. No entanto, a Instituição ainda não realiza a avaliação 360 graus, embora os servidores docentes sejam avaliados pelos alunos. 


\section{GESTÃO DE PESSOAS EM UM INSTITUTO FEDERAL DE EDUCAÇÃO, CIÊNCIA E TECNOLOGIA \\ DOI: http://dx.doi.org/10.5007/1983-4535.2012v5n2p129}

Nas políticas de relações de trabalho, observa-se que a Instituição apresenta vários canais de comunicação com a comunidade interna e externa, de forma virtual e impressa, o que significa um ponto positivo a ser destacado para o Instituto.

Quanto à participação da comunidade na gestão, destaca-se que a Instituição apresenta uma gestão participativa, com diversos meios de propiciar essa prática. Salienta-se que a participação da comunidade gera um sentimento de corresponsabilidade nas tomadas de decisões. Já quanto aos relacionamentos, são identificadas ações culturais, de lazer e confraternização nos campi, ações estas não institucionalizadas.

No que se refere ao reconhecimento, o Instituto possui poucos mecanismos de reconhecimento dos seus servidores.

Por fim, em relação à política de Seguridade Social, a Instituição aderiu ao SIASS para questões referentes a doenças, seguridade social e acidentes de trabalho, e não possui uma política interna de planejamento, prevenção e controle de riscos da área de segurança do trabalho.

\section{CONSIDERAÇÕES FINAIS}

As políticas de capacitação e desenvolvimento de pessoas, tanto aquelas instituídas pelo governo como as do próprio Instituto, têm orientações, regras e princípios que dão atenção à valorização dos servidores e o que se chamou de tratar bem. Mas há a necessidade de potencialização em alguns aspectos: atualizar o mapeamento de competências a partir do cenário de expansão da Instituição; implantar metodologia de avaliação de resultado das ações de capacitação; promover ações de capacitação gerencial e considerar essas ações como requisitos para que os servidores assumam cargos de direção e função gratificada.

O Instituto não apresenta ações que contemplem a qualidade de vida, saúde e segurança no trabalho; portanto, sugere-se que sejam instituídos programas com esses enfoques. Sugere-se também que sejam desenvolvidos programas e ações que fomentem os relacionamentos sociais na Instituição, a fim de proporcionar maior integração entre os servidores, bem como o sentimento de pertencimento para com o Instituto.

Outra oportunidade de melhoria identificada pela pesquisa refere-se ao reconhecimento dos servidores, considerando os resultados positivos alcançados por eles, ideias inovadoras, produtividade, entre outros. 


\section{GESTÃO DE PESSOAS EM UM INSTITUTO FEDERAL DE EDUCAÇÃO, CIÊNCIA E TECNOLOGIA \\ DOI: http://dx.doi.org/10.5007/1983-4535.2012v5n2p129}

Por último, quanto à avaliação de desempenho, apesar de apresentar um enfoque alinhado com a gestão por competências, pelos resultados alcançados pela pesquisa sugere-se maior sensibilização da comunidade a fim de desenvolver cada vez mais a cultura de avaliação, com o objetivo de implantar uma avaliação 360 graus, que já se encontra prevista na legislação atual.

\section{REFERÊNCIAS}

ALMEIDA, Alcides Vieira de. Da Escola de Aprendizes Artifices ao Instituto Federal de Santa Catarina. Florianópolis: IFSC, 2010.

BRASIL. Constituição da República Federativa do Brasil (1988). Disponível em: $<$ http://www.planalto.gov.br/ccivil_03/constituicao/constitui\%C3\%A7ao.htm>. Acesso em: 3 jan. 2011.

. Lei $n .{ }^{\circ} 8.112$, de 11 de dezembro de 1990. Regime jurídico dos servidores públicos da união, autarquias e fundações públicas federais. Disponível em:

$<$ http://www.planalto.gov.br/ccivil_03/Leis/L8112cons.htm>. Acesso em: 8 mar. 2011.

Lei $n .^{\circ} 11.091$, de 12 de janeiro de 2005. Dispõe sobre a estruturação do Plano de Carreira dos Cargos Técnico-Administrativos em Educação, no âmbito das Instituições Federais de Ensino vinculadas ao Ministério da Educação. Disponível em: $<$ http://www.planalto.gov.br/ccivil_03/_ato2004-2006/2005/lei/111091.htm>. Acesso em: 8 fev. 2011.

. Decreto $n^{\circ}{ }^{\circ}$ 5.707, de 23 de fevereiro de 2006. Institui a Política e as Diretrizes para

o Desenvolvimento de Pessoal da administração pública federal direta, autárquica e fundacional, e regulamenta dispositivos da Lei n. ${ }^{\circ} 8.112$, de 11 de dezembro de 1990. Disponível em: < http://www.planalto.gov.br/ccivil/_Ato20042006/2006/Decreto/D5707.htm>. Acesso em: 20 out. 2010.

Lei $n .{ }^{\circ} 11.784$, de 22 de setembro de 2008. Dispõe sobre a reestruturação do Plano Geral de Cargos do Poder Executivo. Disponível em: $<$ http://www.planalto.gov.br/ccivil_03/_ato2007-2010/2008/Lei/L11784>. Acesso em: 3 jan. 2011.

MINISTÉRIO DO PLANEJAMENTO, ORÇAMENTO E GESTÃO. SECRETARIA DE RECURSOS HUMANOS. Portaria Normativa $n .^{\circ} 3$, de 30 de julho de 2009. Dispõe sobre a assistência à saúde suplementar do servidor ativo, inativo, seus dependentes e pensionistas e dá outras providências. Disponível em:

$<$ http://www.servidor.gov.br/seg_social/arq_down/090730_port_normat_3.pdf $>$. Acesso em: 3 mar. 2011. 


\section{GESTÃO DE PESSOAS EM UM INSTITUTO FEDERAL DE EDUCAÇÃO, CIÊNCIA E TECNOLOGIA \\ DOI: http://dx.doi.org/10.5007/1983-4535.2012v5n2p129}

. MINISTÉRIO DO PLANEJAMENTO, ORÇAMENTO E GESTÃO. SECRETARIA DE RECURSOS HUMANOS. Fórum do Planalto. Secretaria do Planejamento. Política Nacional de Gestão de Pessoas no governo Lula: uma construção negociada e inovadora. Disponível em:

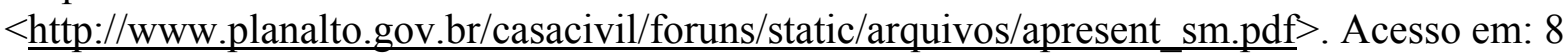
mar. 2011.

MINISTÉRIO DO PLANEJAMENTO, ORÇAMENTO E GESTÃO. SECRETARIA DE RECURSOS HUMANOS. 2011. SIASS. Subsistema Integrado de Atenção à Saúde do Servidor. Disponível em: <https://www1.siapenet.gov.br/saude/>. Acesso em: 8 mar. 2011.

BUHR, Luísa Nedel. Do departamento de pessoal à gestão de pessoas. 2008. Disponível em: <http://hdl.handle.net/10183/16607>. Acesso em: 3 mar. 2011.

DEMO, Gisela. Política de gestão de pessoas nas organizações: papel dos valores pessoais e da justiça organizacional. São Paulo: Atlas, 2005.

FRANCO, Simon. Criando o próprio futuro. 6. ed. São Paulo: Futura, 2002.

GIL, Antonio Carlos. Como elaborar projetos de pesquisa. 4. ed. São Paulo: Atlas, 2007.

GIRARDI, Dante. Da seção de pessoal à gestão estratégica de pessoas: Consultoria Interna de Recursos Humanos. Florianópolis: Pandion, 2008.

Gestão do conhecimento e gestão de pessoas: consultoria interna de RH: conceitos e procedimentos. Florianópolis: Pandion, 2009.

JACOBSEN, Alessandra L.. Áreas de atuação da Administração. In: JACOBSEN, Alessandra L.; CRUZ JÚNIOR, João B.; MORETTO NETO, Luis (Orgs.). Administração: introdução e teorias. Florianópolis: SEaD/UFSC, 2006.

LACOMBE, Francisco J. M. Recursos humanos: princípios e tendências. São Paulo: Saraiva, 2005.

MATTAR, Fauze N.. Pesquisa de Marketing: metodologia, planejamento. 5. ed. São Paulo: Atlas, 1999. v. 2.

PACHECO, Eliezer. Os Institutos Federais: uma revolução na educação profissional e tecnológica. Natal: IFRN, 2010.

PACHECO, Luzia et al. Capacitação e desenvolvimento de pessoas. Rio de Janeiro: Editora FGV, 2009.

SILVA, Jesué G.; SCHROEDER, Nilva; SILVA, Silvana F. P. Do discurso à ação: uma experiência de gestão participativa na educação pública. Blumenau: Nova Letra, 2007. 
GESTÃO DE PESSOAS EM UM INSTITUTO FEDERAL DE EDUCAÇÃO, CIÊNCIA E TECNOLOGIA

DOI: http://dx.doi.org/10.5007/1983-4535.2012v5n2p129

VERGARA, Sylvia C.. Projetos e relatórios de pesquisa em administração. 8. ed. São Paulo: Atlas, 2007. 